\title{
TAUTAN KONTEKS SITUASI DAN KONTEKS BUDAYA: KAJIAN LINGUISTIK SISTEMIK FUNGSIONAL PADA CERITA TERJEMAHAN FIKSI "HALILIAN"
}

\author{
Rosmawaty \\ Fakultas Bahasa dan Seni Universitas Negeri Medan \\ email: arnita22@yahoo.com
}

\begin{abstract}
Halilian is a prose or story presented in a relaxing situation or leisure time. The Angkola community's social reality, local wisdom, socio-cultural values, and ideology reflected in the Halilian text can be revealed through a systemic functional linguistics study. This study tries to reveal the social construction, comprising men's and women's positions and roles in society. Human relations and life nuances due to the relations vary, depending on the problems that each actor encounters. Human beings have problems related to family and society. The findings show that in the Angkola culture: (1) it is necessary to pay a visit to parents wherever one lives because this has effects on life, (2) one must keep promise, (3) there is still a belief in spirits, and (4) the husband-wife interaction is a one way interaction, with the husband's power being stronger than the wife's.
\end{abstract}

Keywords: context relevance, intertext, socio-cultural context, systemic functional linguistics

\section{PENDAHULUAN}

Cerita prosa dalam tradisi sastra Angkola disebut Halilian (cerita waktu). Halilian dipandang sebagai jenis cerita yang biasanya disampaikan dalam suasana santai atau disampaikan sebagai cerita perentang waktu. Karena sifat penyampaiannya yang demikian, teks cerita pada Halilian umumnya pendekpendek dan hampir selalu merupakan cerita yang penuh dengan unsur-unsur nasihat. Teks ini menceritakan gambaran sosial yang terjadi dalam kehidupan manusia. Gambaran sosial dalam teks Halilian ini lahir sebagai hasil kepekaan jiwa pengarang untuk mengungkapkan imajinasinya. Secara intrinsik, fiksi teks terjemahan Halilian ini memiliki genre yang sama, yaitu prosa naratif yang dibangun oleh elemen struktur tema dan latar belakang budaya Angkola.

Prosa diungkapkan melalui baha- sa yang menjalankan fungsinya untuk memaparkan, mempertukarkan, dan merangkai pengalaman sesuai dengan konteks. Menurut Saragih (2006 : 23), konteks adalah aspek-aspek internal teks dan segala sesuatu yang secara eksternal melingkupi teks. Saragih juga mengatakan bahwa bahasa merupakan fenomena sosial yang wujud sebagai semiotik sosial dan bahasa merupakan teks yang berkonstrual (saling menentukan dan merujuk) dengan konteks sosial.

Linguistik Sistemik fungsional (LSF) adalah salah satu aliran kajian bahasa fungsional yang mengkaji makna teks. Aliran ini mengembangkan sebuah teori bahasa dengan memandang bahasa sebagai suatu proses sosial. Dengan kata lain, aliran tersebut mencari caracara bahasa yang digunakan manusia yang tersusun dalam konteks-konteks 
yang berbeda (konteks situasi dan konteks budaya). Di samping konteks situasi, sebuah teks juga dibangun oleh konteks budaya. Konteks budaya mengacu pada nilai yang dianut oleh sekelompok orang (masyarakat). Halliday (1992:63) mengatakan bahwa setiap konteks situasi yang sebenarnya, susunan medan tertentu, pelibat dan sarana yang telah membentuk teks itu, bukanlah suatu kumpulan ciri yang acak, melainkan suatu keutuhan sebagai suatu paket yang secara khas bergandengan dalam suatu budaya. Oleh karena itu, LSF dipandang relevan untuk mengkaji teks Halilian terkait dengan pengungkapan konteks situasi dan konteks budaya.

Sesungguhnya sastra tradisional berbeda dengan sastra modern. Sastra tradisional disesuaikan dengan konvensi sastra yang berlaku dalam zamannya, sedangkan sastra modern adalah sastra yang cenderung menyimpang dari tradisi/konvensi. A. Teeuw, mengutip Lotman, mengatakan bahwa karya sastra tradisional telah menetapkan harapan penikmat dalam struktur karya yang telah diberikan sebelumnya. Sistem artistik semacam ini disebut estetika identitas, sedangkan karya sastra modern disebut mempunyai dasar estetika pertentangan (Teeuw, 1983: 26-27).

Gayut dengan estetikia identitas Lotman, teori estetika resepsi Hans Robert Jauss (1982) mengungkapkan bahwa sambutan penikmat sastra diarahkan oleh horizon harapan dan merupakan interaksi antara karya itu dengan penikmat. Ia merupakan proses dialektik antara produksi dan proses interaksi antara pencerita dengan khalayak penikmat (Holuh, 1986:58). Dalam visi Goldman (1981: 111-112), publik menyambut karya sastra tertentu karena sesuai dengan pandangan dunia kelompok tersebut. Pandangan dunia dimaksud mempunyai perspektif koheren, mengandung fakta historis dan sosial, dan merupakan totalitas berpikir, berasa, dan bertindak

Untuk memahami makna sebuah teks sastra penting pula dipertimbangkan sumbangan karya-karya terdahulu yang mungkin menimbulkan berbagai signifikasi (Guller, 1981:103). Aspek intertekstual semacam ini disebut oleh Riffaterre (1979:94) sebagai hipogram. Teks lain yang menjadi hipogram tidak hadir begitu saja dalam karya itu. Ia muncul dalam proses pemahaman dan harus disimpulkan sendiri oleh penikmat. Hubungan intertekstual semacam itu dalam kehidupan sastra tradisional tampaknya erat kaitannya dengan konvensi sastra yang secara kolektif dihayati sehingga kedudukan/peran pengarang menjadi tidak penting.

Situasi kehidupan yang beredar dari mulut ke mulut dan diwariskan kepada generasi berikutnya secara lisan membuka kemungkinan luas bagi perubahan karya sastra dalam pergeseran ruang dan waktu. Pelbagai karya lainnya pastilah tidak terhindarkan. Begitu pula penurunan cerita Hallian "Si Baginda Napal Hatoguan" yang dilakukan oleh Prof. Dr Abdurrahman Ritonga M.Pd. Karya ini dapatlah dipandang sebagai hasil sambutan dari yang bersangkutan dalam penghayatan ruang dan waktu yang dialami. Usaha untuk merujuk salinan ini kepada cerita yang mungkin masih beredar sekarang di kalangan masyarakat Angkola pastilah akan membawa hasil yang memuaskan, sebab cerita itu pun tentu sudah mengalami perubahan pula.

Cerita "Si Baginda Napal Hatoguan" yang penulis sajikan dalam bentuk terjemahan ini memperlihatkan hubungan intertekstual yang begitu banyak. Hubungan tersebut tentulah mempunyai efek signifikasi untuk karya ini. Intertekstual akan melahirkan interrelasi konteks. 
Konteks adalah aspek-aspek internal teks dan segala sesuatu yang secara internal melingkupi teks. Dengan demikian, secara garis besar, konteks dapat dibedakan atas (1) konteks bahasa dan (2) konteks luar bahasa (extra linguistic contenxt), yang disebut "konteks stuasi" dan "konteks budaya (Saragih, 2003:4). Menurut Sumarlan (2006:14), konteks merupakan dasar bagi inferensi. Yang dimaksud inferensi di sini adalah proses yang harus dilakukan oleh komunikan (pendengar/pembaca/mitra tutur) untuk memahami makna sehingga sampai pada penyimpulan maksud dan tuturan.

Berdasarkan telaah dari segi konteks, tampak bahwa konteks situasi sangat besar peranannya untuk memahami teks. Di samping itu, analisis konteks situasi dapat memberikan makna yang cukup besar terhadap teks terjemahan karena terjadinya pergeseran akibat adanya konteks situasi dan konteks budaya. Apabila konteks budaya merupakan dasar bagi pemahaman makna teks, maka konteks situasi dapat dipandang sebagai pembatas makna, karena konteks situasi terjadi dari tiga komponen, yaitu bidang atau isi (field), pelibat (participant), dan cara (mode).

Konteks Budaya dibatasi sebagai kegiatan sosial yang bertahap dan berorientasi tujuan (Martin 1986 dalam Saragih 2003:198). Teks merupakan kegiatan atau aktivitas sosial dengan pengertian bahwa teks wujud sebagai interaksi yang melibatkan dua sisi pelibat: pembicara atau penulis dan pendengar atau pembaca. Budaya pemakai bahasa menetapkan apa yang boleh dilakukan oleh partisipan tertentu dengan cara tertentu pula. Dengan kata lain, konteks budaya secara rinci menetapkan konfigurasi unsur isi, pelibat, dan cara. Misalnya, khotbah membicarakan ajaran agama (isi) yang melibatkan khatib atau pendeta dan jemaah atau jemaat (pelibat) dengan interaksi satu arah saja (cara). Berbeda dengan khotbah, pengajian atau pénelaah kitab membicarakan agama (isi) yang melibatkan ustad atau pengetua dan jemaah atau jemaat (pelibat) dengan interaksi dua arah (cara). Khotbah dan pengajian dapat melibatkan isi dan pelibat yang sama dan perbedaan utama adalah perbedaan dalam cara.

Konteks budaya juga menetapkan tahap (stages) yang harus dilalui untuk mencapai suatu tujuan karena pemakai bahasa tidak mungkin mencapai suatu tujuan dengan hanya sekali ucap. Dengan kata lain, konteks budaya menetapkan langkah yang harus dilalui untuk mencapai tujuan sosial suatu teks. Langkah atau tahap itu di sebut struktur teks (generic atau schematic structures). Berdasarkan tujuan sosialnya, teks dapat dikelompokkan ke dalam beberapa jenis, seperti argumentasi, diskusi, laporan, dan narasi, yang masing-masing meiliki struktur tertentu.

Konteks budaya (genre) merupakan suatu pendekatan yang menggambarkan cara-cara manusia menggunakan bahasa untuk mencapai tujuan sesuai dengan budaya yang melingkupinya. Analisis genre teks Halilian difokuskan pada struktur genre teks yang akan membentuk koherensi generik.

\section{METODE}

Objek penelitian ini berupa terjemahan teks karya sastra fiksi berbahasa Indonesia (teks target). Teks ini berasal dari teks sumber berbahasa Angkola. Pemilihan teks ini didasari oleh pemikiran bahwa karya sastra adalah produk penggunaan bahasa. Dengan demikian, karya sastra, apapun wujudnya (genre), dapat dipahami selaras dengan hakikat bahasa itu sendiri, yakni sebagai suatu sarana untuk mengkomunikasikan 
pesan pengarangnya kepada pembaca. Dengan demikian, walaupun karya sastra merupakan suatu hasil karya imajinatif namun karya tersebut muncul melalui proses kreatif, termasuk kreativitas berbahasa. Kreativitas berbahasa merupakan hasil kemampuan retorik pengarang yang bisa dipandang sebagai perfomance. Identik dengan parole, performance merupakan objek kajian dalam penelitian linguistik maupun pragmatik. Hasil karya sastra terjemahan Halilian tidak saja menunjukkan perilaku sosial manusia tetapi juga proses sosialisasi, dan berbicara tidak saja pengalaman individu tetapi juga makna dari pengalaman tersebut.

Objek kajian dalam penelitian ini adalah teks terjemahan yang berupa fiksi. Genre fiksi ini dilihat sebagai suatu upaya komunikasi kebahasaan karena teks fiksi tersebut mengkomunikasikan cerita dengan menggunakan bahasa. Menurut Tarigan (1992:7), teks fiksi dapat dikaji sebagai suatu tindak bahasa yang terjadi pada dua tataran: (1) tataran luar fiksi dan (2) tataran dalam fiksi. Komunikasi pada tataran luar fiksi merupakan upaya menyampaian amanat tertentu dari pengarangnya melalui isi (fiksi) itu yang di tunjukkan kepada suatu publik pembaca yang diperkirakan pengarang. Sementara itu, komunikasi pada tataran dalam fiksi adalah pencapaian cerita dari pencerita kepada pembacanya. Identik dengan apa yang dikatakan Tarigan (1992) bahwa genre fiksi adalah suatu upaya komunikasi kebahasaan. Penelitian "Kajian Terjemahan Teks Bahasa Angkola", ini fiksi adalah mengkaji teks yang ditulis oleh penerjemah dan sekaligus dilihat sebagai kegiatan komunikasi. Teks fiksi yang dijadikan objek kajian terjemahan adalah: Terjemahan "Baginda Napal Hatoguan" Karya Abdurrahman Ritonga dalam kumpulan Turi-turian ni Halak Angkola, berjudul "Halilian".

\section{HASIL DAN PEMBAHASAN}

Tautan Konteks Situasi dan Konteks Budaya pada Teks-Teks Terjemahan

Konteks adalah aspek internal teks dan segala sesuatu yang secara eksternal melingkupinya. Analisis konteks ini meliputi konteks situasi dan konteks budaya. Apabila konteks budaya merupakan dasar bagi pemahaman teks terjemahan, maka situasi yang dikaji dibatasi pada komponen utama, field, tenor, mode. Field atau medan merujuk pada apa yang sedang terjadi dalam teks dan sifat-sifat proses sosial: apa yang sedang dilakukan partisipan dengan menggunakan bahasa sebagai mediumnya, atau sebagai 'the social action'. Tenor atau pelibat adalah 'the role structure' mengacu kepada siapa yang berperan di dalam kejadian sosial tersebut, sifat-sifat partisipan, status dan peran sosial. Mode atau sarana adalah 'the symbolic organization' merujuk pada bagian yang diperankan oleh bahasa. Hal ini menyangkut harapan partisipan dengan menggunakan bahasa dalam situasi tertentu: organisasi simbolik teks, status yang dimilikinya, fungsinya dalam konteks, saluran (channel): tertulis atau lisan atau gabungan keduanya, sarana retoris: persuasif, ekspositoris, didaktis, dan sejenisnya.

Analisis kontekstual dalam penelitian ini menitikberatkan pada konteks situasi. Pemahaman konteks situasi dapat dilihat pada data berikut:

Bia ma he'ttong baenon, rupa madung sibat di na mardunia on do. Muda taradong di iba, kecet pe mur bahat. Na pola maralang-alang iba makkuling gogo di lopo-lopo. Bisa muse iba mandok sipaingot tu halak, on na tusi on na tuson Bope na so tutu nadidokkonan i, halak pe na bagi aha didokkon na manangihon kalak. Anggo hum na ditangihon, napola hatcit di lala. Tai muda batcing mata ni na mambegesa, nama murdangol dilala. Hohom kohom iba, didokkon halak iba si longas. Songon na didokkon halak Huta- 
suhut i, sip muap bau, makkuling muap et. Tarsongon i ma si Tigor, sai hohom kohom. Saba sibaenon pe na sadia, nadilehen kalak. Tarpaksa ma ia sai kehe mai soban atco bisa manyambung ngolu. Anggo sabotulna, na mai soban on pe nanggo nataromo. Pas-pas mai i bisa manobusi dahanon dua tolu takar. Giot manggotti sattut pe maol. Tai benna so adong pangomoan nadong haimbaran, bia jo labuna. Holi-holi pe mapukpuk, na diomo so suada.(pepatah)

'Bagaimana mau dibuat sudah sifat kehidupan, kalau ada pada kita, bicarapun semakin banyak dan bersama orang banyakpun kita tidak segan apa yang mau dikatakan (S27). Kita dapat memberikan nasihat kepada orang lain tentang apa yang mau dikatakan walaupun yang kita katakan tidak benar tetapi sakit hati orang yang mendengar (S28). Kalau orang susah lebih banyak diamnya(S29). Seperti yang dikatakan orang Hutasuhut, diam bau sekali, berbicara bau kotoran. Seperti itulah si Tigor, selalu diam saja. Orang yang memberikan sawah untuk dipakai pun tidak banyak, karena itulah dia pergi mencari kayu bakar untuk menyambung hidupnya (S30). Hasil dari mencari kayu bakar itu tidak seberapacukup untuk memberi beras dua atau tiga takaran(S31). Mau mengganti sendal pun susah karena tidak ada
uang(S31). Bekerja keras pun dilakukan sampai tulang keropos tetapi hasilnya tak ada.(pepatah).'

Berdasarkan analisis konteks situasi melalui penafsiran personal dapat dilihat gambaran kehidupan orang kaya di Angkola. Orang kaya lebih memiliki kesempatan mengemukakan pendapat dibandingkan orang miskin/orang biasa. Kesempatan orang kaya tersebut dapat dibandingkan dengan orang susah seperti "Si Tagor". Selain pemahaman konteks situasi seperti tersebut di atas, ada juga konteks sosial dan situasional yang perlu dipertimbangkan dalam mengkaji teks terjemahan. Dalam analisis sosial budaya, interrelasi dengan konteks situasi dapat dilakukan dengan analisis cara (mode).

Cara atau mode menunjukkan bagaimana peran bahasa dalam interaksi. Secara rinci, cara menunjukkan peran bahasa dalam satu interaksi, harapan pelibat terhadap peran bahasa dalam suatu situasi, status bahasa dan mediun atau saluran (channel). Unsur yang membangun cara terdiri atas keterencanaan (planning), jarak, dan medium, atau saluran. Deskripsi hasil analisisnya dapat dilihat pada tabel 1 .

Tabel 1: Deskripsi Register Teks Terjemahan

\begin{tabular}{|c|c|c|c|}
\hline \multirow{2}{*}{$\begin{array}{l}\text { Tema Teks } \\
\text { Terjemahan }\end{array}$} & \multicolumn{3}{|c|}{ Va Riabel Register } \\
\hline & Medan/ Field & Mode & Pelibat/tenor/participant \\
\hline \multicolumn{4}{|c|}{ Tema1: Hubungan manusia dengan manusia } \\
\hline Teks: BNH & $\begin{array}{l}\text { Narasi tentang } \\
\text { abang dan adik } \\
\text { akibatkan harta } \\
\text { warisan yang } \\
\text { Ditinggalkan orang } \\
\text { tua menjadi } \\
\text { pertengkaran. Anak } \\
\text { yang lupa untuk } \\
\text { mengenang orang } \\
\text { tua sehingga lupa } \\
\text { untuk menjiarahinya. }\end{array}$ & $\begin{array}{l}\text { Pembicaraan langsung } \\
\text { satu arah dengan bentuk } \\
\text { klausa deklaratif } \\
\text { informatif. Tema } \\
\text { didominasi oleh } \\
\text { sirkumstan waktu dan } \\
\text { ruang serta tema } \\
\text { Topical, yaitu sebagai } \\
\text { pelaku, aktor dan } \\
\text { komunikator. }\end{array}$ & $\begin{array}{l}\text { Partisipan } \\
\text { mempunyai kontak } \\
\text { agak informal, } \\
\text { dengan frekuensi } \\
\text { pertemuan tinggi, } \\
\text { dan kekuasaan } \\
\text { yang sama antara } \\
\text { partisipan manusia } \\
\text { (Si Sakkot dan } \\
\text { putri Raja yang }\end{array}$ \\
\hline
\end{tabular}




\section{Keterencanaan}

Keterencanaan menunjukkan persiapan yang di lakukan untuk mewujudkan teks. Interaksi dapat terjadi dengan skenario yang telah direncanakan lebih dahulu dan dapat pula terjadi tanpa rencana, terjadi apa adanya, atau berlangsung secara spontan.

\section{Jarak}

Jarak mengacu kepada umpan balik (feedback) yang saling di berikan antarpelibat atau antarpemakai bahasa dan keterbabitan atau keikutsertaan bahasa dengan realitas yang di wakilinya. Berdasarkan analisis dan data teks $\mathrm{BNH}$, apakah umpan balik yang di berikan seorang pelibat dapat langsung di tanggap oleh pelibat lainnya atau tidak. Dalam interaksi bersemuka kedua pelibat dapat secara langsung dan segera memberi dan menanggap umpan balik.

Keterbabitan bahasa dengan realitas menunjukkan tingkat teks atau bahasa dengan kegiatan yang di lakukan. Dengan kata lain, keterbabitan ini menujukkan jarak teks dan realitas yang di wakili. Secara rinci, dapat di katakan bahwa di satu sisi teks yang di gunakan dapat langsung mewakili aktivitas yang berlangsung, seperti teks $\mathrm{BNH}$ yang secara langsung meliput satu kejadian yang terjadi pada masyarakat dahulu. Di sisi lain jarak antara teks dan aktivitas dapat sangat jauh seperti dalam teks BNH yang membicarakan ulasan tentang tentang kehidupan manusia.

\section{Medium dan Saluran dalam Teks Ter- jemahan}

Medium atau saluran menunjukkan sarana yang di realisasikan bahasa. Medium terdiri atas dua unsur yang merupakan kontinum, yaitu tulisan. Antara bahasa lisan dan tulisan terdapat variasi teks yang melibatkan keduanya dengan proporsi yang berbeda. Misalnya, komunikasi lisan.

Legenda Turi-Turian ni halak Angkola penelitian ini merupakan bahasa tulis satu arah (monolog), yaitu dari pencerita kepada pendengar dengan dialog di dalamnya, yaitu dialog antarpelibat, seperti dialog antara manusia dengan manusia, manusia dengan jin, manusia dengan orang pintar.

Hubungan unit frasa terhadap klausa dan hubungan unit kata terhadap frasa seperti yang dikemukakan di atas adalah hubungan eksponensial normal, yakni hubungan yang merepukan konsekuensi dari kedudukan masingmasing dalam tataran gramatikal. Selain hubungan eksponensial yang normal seperti itu, pada kenyataannya masih ada hubungan eksponensial yang lain yang dapat dikatakan sebagai hubungan eksponensial non-normal. Hubungan non-normal dalam hal ini dimaksudkan suatu unit bisa memiliki kondisi hierarki yang berbeda dibandingkan dengan hierarki gramatikal normal. Hubungan eksponensial non-normal unit klausa terhadap frasa diperlihatkan melalui contoh berikut.

(109) Sonang roha ni si Sakkot mambege hata ni ina-ina I, songon na_mandapot aek inuman di halak na manguas. $(\mathrm{BNH})$

Struktur yang bergaris bawah dalam contoh (109) merupakan unit frasa yang bersruktur I + Qualifier (Q). Meskipun secara normal elemen I-nya memang direalisasi oleh sebuah kata, yaitu, Sonang namun elemen Q-nya tidaklah demikian adanya. Pengisi elemen $Q$ ini bukan sebuah kata, tetapi justru sebuah klausa, yaitu klausa relatif mambege hata ni ina-ina $i$. Dari ilustrasi tersebut bisa dimengerti bahwa hubungan eksponensial non-normal unit klausa tersebut terhadap unit frasa ber- 
sangkutan ditunjukkan oleh beroperasinya unit klausa sabagai pengisi salah satu elemen struktur unit frasa, atau dengan kata lain beroperasinya sebuah unit yang lebih tinggi rank-nya di dalam sebuah unit yang lebih rendah.

Di samping identitas berdasarkan kedudukan atau statusnya dalam tataran gramatikal serta berdasarkan sifat hubungannya terhadap unit-unit pada rank di atas dan di bawahnya, identitas unit bisa juga ditentukan melalui kriteria potensial. Penentuan identitas unit melalui kriteria potensial ini diilustrasikan dengan contoh-contoh berikut.

(110) Raja bolon I parsonduknia dua. $(B N H)$

\section{(111) A: Horas?} $B$ : Horas!

Klausa pada contoh (85) ini ber-

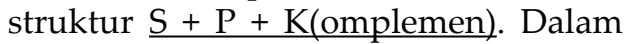
kondisi normalnya, seperti dikemukakan di muka, eksponen struktur klausa adalah unit frasa. Dengan demikian unsur Raja yang kalau berdiri sendiri hanya merupakan sebuah kata, berdasarkan potensinya sebagai pengisi elemen $S$ dapat digolongkan sebagai sebuah frasa, yakni frasa potensial. Potensi ke-frasaan dari kata Raja sebagai pingisi elemen $S$ pada struktur klausa di atas lebih jauh dapat dipertegas dengan mengaplikasikan suatu tes terhadapnya, yaitu suatu tes yang disebut tes perluasan. Sebagai pengisi elemen $S$ kata Raja dapat diperluas misalnya menjadi yang secara berturut-turut memang menjadi, Raja yang meminpin sebuah kerajaan frasa sejati dan klausa nomina dependen, bukan lagi frasa potensial. Begitu pula halnya dengan pengisi elemen K (interesting) yang memiliki potensi untuk dikembangkan menjadi very interesting sehingga bukan lagi berwujud frasa potensial tetapi frasa adjektiva sejati.

Lebih dari pada itu, dari segi potensinya untuk menjadi suatu satuan ujaran dalam komunikasi, sebuah kata atau frasa (frasa nomina misalnya) dapat pula berfungsi sebagai sebuah kalimat. Dasar pengkatagorian sebagai kalimat dalam hal ini bukan karena dipenuhinya kriteria struktur kalimat, tetapi hanya karena kata atau frasa tersebut dapat berfungsi sebagai satuan ujaran dalam komunikasi atau dalam wacana, khususnya sebagai respon terhadap suatu pertanyaan (initiating speech). Dalam contoh (3) walaupun horas hanya merupakan sebuah ajektif, namun dilihat dari segi fungsinya dalam wacana, yaitu sebagai respon terhadapn pertanyaan Horas? Maka dapatlah dikatakan bahwa Horas merupakan sebuah kalimat, yaitu sebuah kalimat potensial, walupun statusnya memang dependen terhadap kalimat pertanyaannya.

Berdasarkan teks sumber dapat ditemukan dari identifikasi unit berdasarkan struktur internal menganggap bahwa suatu unit frasa misalnya adalah pembawa struktur tertentu yang berpola rangkaian elemen dan menilai kelas-kelas frasa yang penting adalah frasa verba yang beroperasi pada $\mathrm{P}$ di dalam struktur klausa, frasa nomina yang beroperasi pada A. Karena sebagian besar data penemuan makna berkonteks budaya muncul dalam bentuk frasa nomina. Teori ketransitifan bersumber dari fungsi representasi bahasa. Halliday (1985:101) memandang bahwa kepemilikan fundamental bahasa memungkinkan manusia membangun gambaran mental realitas, membuat makna dari pengalaman apa yang terjadi di sekitarnya dan di dalamnya. Halliday menekankan pada pentingnya klausa karena klausalah yang sangat berperan dalam perwujudan dalam sistem ketransitifan.

Hubungan antara teks dan struktur sosial bersifat tidak langsung dan dimediasikan teks dan konteks. Teks yang 
dimediasikan oleh wacana berhubungan dengan tahap interpretasi dan selanjutnya teks yang dimediasikan oleh konteks berhubungan dengan tahap eksplanasi. Menurut Fairclough (1989:99), interpretasi dihasilkan melalui kombinasi apa yang ada dalam teks dengan apa yang ada dalam penafsir. Dua hal yang menjadi bahan untuk interpretasi adalah interpretasi teks dan interpretasi konteks.

\section{Konteks Budaya pada Teks Halilian}

Konteks budaya menetapkan langkah yang harus dilalui untuk mencapai tujuan sosial suatu teks. Langkah atau tahap itu di sebut struktur teks ( $g e-$ neric atau schematic structures). Berdasarkan tujuan sosialnya, teks ini adalah narasi.

Teks narasi ini menceritakan kisah legenda masyarakat Angkola. Dalam membicarakan isi, penulis mengambil satu dari dua kemungkinan sisi pandang, yaitu sisi protagonis (yang menyetujui atau mendukung suatu isu sosial) atau sisi antagonis (yang membantah atau menentang isu sosial itu).

Konteks budaya (genre) merupakan suatu pendekatan yang menggambarkan cara-cara manusia menggunakan bahasa untuk mencapai tujuan sesuai dengan budaya yang melingkupinya. Genre teks Halilian ditemukan, struktur genre teks yang akan membentuk koherensi generik.

\section{Struktur Skematik Genre Teks}

Genre Teks mempunyai struktur skematik yang membentuk koherensi teks secara generik, yang tertuang dalam konstituensi (constituency) dan pemberian label (labelling)

Dengan demikian, deskripsistruktur skematik pada teks $\mathrm{BNH}$ adalah: abstrak $\wedge^{\wedge}$ orientasi $1^{\wedge}$ aksi $1^{\wedge}$ orientasi 2 $\wedge$ aksi $\operatorname{komplikasi}^{\wedge}$ resolusi ${ }^{\wedge}$ evaluasi ${ }^{\wedge}$ koda. Penanda teks BNH yang mempunyai latar daerah Angkola ditunjukkan oleh label 'orientasi'. Deskripsi struktur skematik BVD adalah: abstrak $\wedge^{\wedge}$ orientasi $1^{\wedge}$ aksi $1^{\wedge}$ orientasi $2^{\wedge}$ aksi $2^{\wedge}$ aksi komplikasi ${ }^{\wedge}$ resolusi ${ }^{\wedge}$ evaluasi ${ }^{\wedge}$ koda. Deskripsi struktur skematik NPR adalah : abstrak ${ }^{\wedge}$ orientasi $1^{\wedge}$ orientasi $2^{\wedge}$ aksi $1^{\wedge}$ aksi $2^{\wedge}$ orientasi $3^{\wedge}$ aksi $3^{\wedge}$ orientasi $4^{\wedge}$ aksi $4^{\wedge}$ komplikasi ${ }^{\wedge}$ resolusi ${ }^{\wedge}$ evaluasi $\wedge$ koda. Penanda teks Halilian yang mempunyai latar suatu tempat daerah perkampungan dekat sungai ditunjukkan oleh label 'koda' dan secara implisit 'abstrak juga memberikan penanda 'orang'.

Dalam gambaran data dapat dikemukan bagaimana tautan konteks situasi dan konteks budaya. Gambaran tema I tersebut dapat menggambarkan "Hubugan manusia dengan manusia" gambaran hubungan manusia tersebut adalah dilihat dari beberapa aspek kehidupan manusia yang tergambar dalam fiksi dan berkaitan juga dengan kehidupan manusia sekarang. Nuansa kehidupan yang ditimbulkan oleh hubungan ini sangat bervariasi pula, tergantung pada persoalan yang sedang dihadapi tokoh. Gambaran ini dimaksudkan sebagai gambaran manusia yang mempunyai masalah dengan orang lain.

Gambaran tema 2. Gambaran sosial dalam hubungan manusisa dengan Tuhan". Manusia tidak akan hadir di dunia ini tanpa kehendak Tuhan. Karena itu sebagai makhluk Tuhan manusia tidak dapat menolak Takdir. Gambaran manusia dalam hubungan dengan Tuhan dimaksud sebagai gambaran yang disebabkan oleh adanya perasaaan cinta dan perasaan berbakti kepada-Nya.

Gambaran tema 3. Gambaran manusia dengan alam sekitarnya (makhluk halus). Alam secara umum sangat mempengaruhi gambaran manusia. Pada alam yang bergunung-gunung 
yang membuat suara tidak tembus sehingga dalam pembicaaraan harus berbicara keras. Sehingga orang yang tinggal dipegunungan suaranya keras-keras seperti dalam teks 3 ini. Gambaran manusia dalam hubungannya dengan alam adalah mendambakan keindahan alam dan mempunyai kecintaan terhadap alam mencintai udara segar dan nyaman sehungga si Sakkot karena menginginkan keindahan itu ia percaya kepada alam gaib.

Berdasarkan temuan bahwa "medan makna atau semantik field dalam gambaran dari teks menggambarkan bagian dari bidang kebudayaan atau realitas alam semesta tertentu dan direalisasikan oleh seperangkat unsur leksikal. Kebudayaan tidak saja dibangun dari faktor ektrinsik yang muncul sebagai kebudayaan eksplisit tetapi juga oleh faktor intrinsik seperti kepercayaan, nilai norma yang dipahami. Penggunaan bahasa tidak terlepas dari norma atau perspektif yang ada pada dirinya secara internal. Norma tersebut berpengaruh terhadap penggunaan bahasa sesuai dengan faktor lingkungan tersebut melibatkan dua faktor yaitu faktor budaya (genre) dan faktor situasi (register) yang di sebut tataran ektralinguistik (Gurning, 2005:30). Dan pola pengembangan ide atau pesan dan sekaligus penyampaian pesan atau informasi secara efektif penulis memberikan informasi yang dibutuhkan yang kadangkala orang tidak menghiraukannya seperti berjiarah ke makam orang tua dan masalah pentingnya diketahui tentang akibat dari keserakahan dalam pemerolehan harta warisan dan perkawinan merupakan perlakuan yang sakral. Dalam deskripsi register teks terjemahan di atas tergambarkan hal tersebut. Konteks situasi dan budaya sangat mempengaruhi karena: 1) dari Konteks situasi maka timbul konteks budaya, dan 2) konteks situasi dalam teks terjemahan bahwa keluarga adalah sesuatu yang sangat penting, tetapi karena harta maka nilai kekeluargaan menjadi hilang. Sehingga nilai-nilai kekeluargaan dikesampingkan. Seperti yang tergambar pada data. Pemahaman mengenai konteks budaya, sekaligus konteks sosial

\section{Teks Sumber}

Adong do sada uhum, uhum ni Tuhan Na Uli basa i taringotdi harto teanan. Uhum i tar songon on. Muda ise na makkojartu tu harto teanan, harto pusako, harto na dikorjania $i$ akkon parohon parmaraan tusia tu pudi ni ari, sanga hamagoan tu halakna i, manjadi bala tu makkojar harto i. Maksud ni na makkojar tu, tarsongon muse. Bagiannia akkon lumobi, akkon umbahat sian bagian ni akkang sanga angginia. Dibaen ia do usaho bia atco sumurung ia bope dohot dalan margabus. Uppamana, ia maniop podang panjang dohot magondam-ondam tu halak kahangginia lalu mandokkon, 'ise na barani manjama tano on, anggo na hugotap on' ningia ma. Jadi, disia ma bagian ni tano $i$, bagian ni saba sanga kobun $i$. Tarlobi-lobi bagian ni anak na so marama so marina, anak na madung parjolo amangna sanga inangna mangadop tu jolo ni Tuhan, diurahi bagianna, na mangurahi bagian ni anak na so marama on, nada bagi na piga-piga taon, diujung-ujungna akkon murmur di bagasan pardangolan, parkacitan lalu tu pudi-pudi ni ari. Marragam dalanna bia so putcu ngolunia, ia ma mosok ma hartonia, sanga na marugi ma parboniagania, sanga sikola ni anaknia ma na markattotuan, sanga talu-talu di parjujian ma. Mocom ma disi na mambaen susa ngolunia.

\section{Teks Target}

Ada satu ketentuan dari Tuhan, barang siapa yang mengejar harta pusaka, dan serakah akan ada bala dibelakang hari. Rakus ke harta pusaka maksudnya banyak kurang banyak dan berupaya agar harta pusaka lebih banyak 
kepadanya dengan berbagai macam cara biarpun dengan jalan berbohong agar harta lebih banyak kepadanya dari pada orang lain. Umpamanya; garagara harta tersebut ia mengambil parang dan mengancam keluarganya dengan mengatakan siapa yang berani menjamah harta ini akan kupotong. Karena takutnya, maka harta pusaka sawah dan ladang itu jatuh kepadanya termasuk harta anak yatim yang diluan meninggal orang tuanya dikuranginya bagiannya. Karena kerakusannya terhadap harta pusaka kehidupannya menjadi hancur, sekolah anak-anaknya menjadi tak menentu, seperti kalah dalam perjudian, beraneka ragam cobaan diberikan dalam kehidupannya.

\section{Teks Sumber}

Sonang dohot sak-sak roha ni raja dohot Boru Na Mora mambege hata na $\mathrm{i}$ dohot manigor manyapai muse ma raja i. Aha do halanganna, paboa ma jolo Anggi atco hami boto pasadiohonon nami", ning raja i manyosak. "Akkon digamburi hamu ma jolo kuburan ni Oppu i amatta na dung jumolo Baginda Napal Hatoguan". Manigor mangaku ma raja i di layas ni roha salelengna on, inda jungada halahi tarpikir giot mangamburi kuburan i. Inda pola marattara ari sian hata ni bayo datu i, manigor ma kehe halahi dohot suru-suruanna paturehon kuburan, mambaen handangna, paturehon batu tulpang, paiaskon dohot mangamburi pagitcatkon tano kuburan dohot na asing-asing bia so tama tupa indaon ni simanolong, inda be songon na biaso dipature so dipature. Sude binatang harangan bisa mangalosapi kuburan ni raja bolon i. Dung bagi na piga-piga bulan sian sidung mangamburi kuburan ni Oppu i, baen-baen na $i$, adong ma tarida tanda-tanda bahaso madung digora.

\section{Teks Target}

"Kalau penglihatanku" kata orang pintar itu, "Yang satu ini menjadi tiga. Menurutnya Raja akan memiliki anak, tapi ada halangannya". Senang dan bergembira hati Raja dan Boru Na Mora mendengar kata iti langsung Raja bertanya.

"Apanya halangannya, katakanlah dulu, agar kami tahu mempersiapkan", kata Raja mendesak." Harus diperbaiki kamu dulu kuburan Nenek (Orang tua) yang sudah meninggal Baginda Napal Hatoguan. Langsung Raja mengaku, selama ini memang terabaikan, tidak pernah mereka terpikir mau memperbaiki kuburan itu.

Dari teks di atas diperoleh gambaran sosial masyarakat Angkola sebagai berikut.

1) Budaya Angkola mengisyarakatkan bahwa jangan lupa untuk menjiarahi orang tua di mana pun kita berada karena ada dampaknya bagi kehidupan.

2) Budaya Angkola sangat memegang janji.

3) Budaya Angkola masih mempercayai adanya makhluk halus

4) Dalam budaya Angkola suami istri memiliki interaksi satu arah, power suami lebih tinggi dari istri. Karena budaya berpikir laki-laki dominan tidak tidak ingin dipengaruhi perempuan.

Tautan konteks situasi dan budaya pada teks terjemahan fiksi dapat menjadi wujud fiksasi dan stabilisasi juga pelembagaan realitas, peristiwa, dan pengalaman hidup. Teks terjemahan fiksi sesungguhnya merepresentasikan kontruksi sosial atau bangunan sosisal, termasuk di dalamnya peran dan posisis laki-laki dan perempuan dalam masyarakat gender. Dengan membangun dan menciptakan dunia kehidupan dalam teks terjemahannya kemung- 
kinan penafsiran realitas, peristiwa, atau pengalaman hidup yang diwujudkan.

\section{SIMPULAN}

Keterkaitan konteks situasi dan budaya pada teks terjemahan fiksi dapat menjadi wujud fiksasi dan stabilitasi juga pelembagaan realitas, peristiwa dan pengalaman hidup. Teks terjemahan fiksi sesungguhnya merepresentasikan kontruksi sosial atau bangunan sosial, termasuk di dalamnya peran dan posisi laki-laki dan perempuan dalam masyarakat gender. Dengan membangun dan menciptakan dunia kehidupan dalam teks terjemahannya kemungkinan penafsiran realitas, peristiwa, atau pengalaman hidup yang dijadikan dalam cerita. Gambaran manusia pada: Hubungan manusia dengan manusia, nuansa kehidupan yang ditimbulkan oleh hubungan ini sangat bervariasi, bergantung pada persoalan yang sedang dihadapi masing-masing tokoh. Gambaran ini sebagai gambaran manusia yang mempunyai masalah dengan keluarga dan keluarga (BNH).

\section{UCAPAN TERIMA KASIH}

Artikel ini diangkat dari penelitian mandiri swadana yang dilaksanakan pada tahun 2010. Ucapan terima kasih disampaikan kepada para mahasiswa yang telah membantu pelakasanan pengumpulan data dan kepada mitra sejawat yang telah membantu kegiatan verifikasi dan triangulasi data dan hasil penelitian.

\section{DAFTAR PUSTAKA}

Djajasudarma, T. fatimah.1997. Wacana: Pemahaman dan Hubungan Antar unsur. Bandung: PT Eresco.

Djajasudarma, T. Fatimah. 1999. Semantik 2, Pemahaman Ilmu Makna. Bandung: PT Eresco.

Fishman, Joshua,1985. "Language" dalam Adam Kuper dan Jessika Kuper. The Sosial Science Encyclopedia. London, Boston and Henley

Frawley, William. 1992. Linguistic Semantics. USA: Lawrence Erlbaum Associates, Publishers.

Gurning, Busmin. 2005. Linguistik Terapan. Medan: PPs Unimed.

Larson Mildred L, 1984. Penerjemahan Berdasarkan Makna : Pedoman Untuk Pemadaman Antar Bahasa, edisi terjemahan oleh Kencanawati Taniran. Jakarta : Arcan.

Saragih, Amrin. 2006. Bahasa dalam Konteks Sosial. Medan: PPs Unimed.

Sinar, T.S. 2000. Teori dan Analisis Wacana: Pendekatan Sistemik-Fungsional, Medan: Pustaka Bangsa Press.

Sibarani, Robert. 2007. Prinsip Dasar Linguistik, LPPM, USU.

Sibarani, Robert. 2004. Antropolinguistik, PODA, USU.

Saryono, Djoko. 1997. Representasi Nilai Budaya Jawa dalam Prosa Fiksi Indonesia (disertasi). Malang: Universitas Negeri Malang.

Sumarlam. 2006. Analisis Wacana Tekstual dan Kontekstual. Surakarta: Universitas Sebelas Maret.

Lubis, Syahron, 2009. Penerjemahan Teks Mangupa dari Bahasa Mandailing ke dalam Bahasa Inggeris (Desertasi), Universitas Sumatera Utara.h 